\title{
Effect of the COVID-19 Pandemic on the Number and Diversity of Pediatric Burn Intensive Care Unit Cases: A Cross-Sectional Study
}

\author{
๑ Can Ihsan Oztorun, ๑ Elif Emel Erten*, ๑ Sabri Demir* , ๑ Dogus Guney, ๑ Ahmet Erturk*,

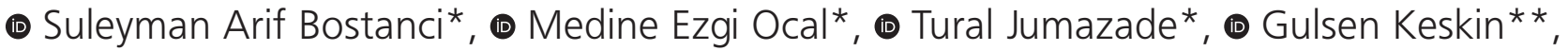 \\ ๑ Mujdem Nur Azili, ๑ Saliha Kanik Yuksek***, ๑ Emrah Senel \\ Ankara Yıldırım Beyazıt Unıversity Faculty of Medicine, Department of Pediatric Surgery, Ankara, Turkey \\ ${ }^{*}$ Ankara City Hospital, Children's Hospital, Clinic of Pediatric Surgery, Ankara, Turkey \\ ${ }^{* *}$ Ankara City Hospital, Children's Hospital, Clinic of Pediatric Anesthesiology, Ankara, Turkey \\ ${ }^{* * *}$ Ankara City Hospital, Children's Hospital, Clinic of Pediatric Infection Diseases, Ankara, Turkey
}

\section{Abstract}

Aim: The Coronavirus disease-2019 pandemic has effects on the healthcare system, as well as on the care of child burns. In our study, we aimed to compare the numbers and demographic data of patients who were treated and followed up during the pandemic period in our burn intensive care center with the data of patients in the same period one year prior.

Methods: The patients who were admitted to our tertiary pediatric burn center were divided into two groups: pandemic period (March 10-September 30, 2020) and pre-pandemic period (March 10-September 30, 2019). The groups were compared in terms of age, gender, city of origin, means of transport to the hospital, total burn surface area, burn etiology, duration of hospitalization, intubation status, and mortality from their medical records.

Results: In the pandemic period group, 414 children were admitted to the pediatric burn unit and 126 (30.4\%) were hospitalized; however, in the pre-pandemic period group, 728 children were admitted to the pediatric burn unit and 98 (13.4\%) were hospitalized $(p<0.01)$. The average total burn surface area was s higher in the pre-pandemic group $(16.31 \%)$ than in the pandemic group $(12.29 \%)$. The intubated patient rate in the pandemic group (17.34\%) was higher than the pre-pandemic group patients ( $p=0.005)$. The mortality rate was $3.1 \%$ in the pandemic group and $5.1 \%$ in the pre-pandemic group.

Conclusion: The rate of hospitalization to burn centers has increased in the pandemic period. However, patients in the pandemic period were mild cases compared to the pre-pandemic period.

Keywords: COVID-19 pandemic, COVID-19 lockdown, burn care, pediatric burns

\section{Introduction}

The novel Severe acute respiratory syndrome Coronavirus-2 and its Coronavirus disease-2019 (COVID-19) has rapidly developed as a pandemic and public health problem (1). The COVID-19 pandemic has placed immense pressure on the healthcare system.
Burns are a serious cause of trauma in all age periods and require emergency medical intervention (2). In children, burns are one of the leading reasons for hospitalization and may require intensive care. Low socioeconomic status, young age, low parental education, and overcrowding are known risk factors for burns (3). Our tertiary care pediatric hospital in the capital city is a pediatric burn referral center

Address for Correspondence: Can Ihsan Oztorun, Ankara Yıldırım Beyazıt Unıversity Faculty of Medicine, Department of Pediatric Surgery, Ankara, Turkey Phone: +90 5062987004 E-mail: drcan-oz@hotmail.com ORCID: orcid.org/0000-0002-5408-2772 Received: 05.05.2021 Accepted: 16.05.2021 
for all pediatric patients countrywide with 12 isolated pediatric intensive care rooms.

In the first COVID-19 wave, home isolation and curfew were implemented in many countries for decreasing social contact and preventing the spread of coronavirus infection (4). In our country, the public was restricted from taking to the streets between March 16 and May 30, 2020. During this period, schools were closed, and children were under curfew for nearly 16 weeks. Meanwhile, no restrictions were imposed on medical services. Although our hospital is a pediatric COVID-19 pandemic center, burn patients have not been restricted because they still need emergency interventions.

In our study, we aimed to compare the numbers and demographic data of patients who were treated in our burn intensive care center and followed up during the pandemic period with the data of patients in the same period one year prior.

\section{Methods}

The present study was approved by both the Republic of Turkey Ministry of Health COVID19 Scientific Commission (date: 08.12.2020, approval number: 874) and the Local Ethics Committee of Ankara City Hospital (date: 09.16.2020, approval number: E1-20-956). Our study is retrospective cross-sectional, therefore patient consent was not obtained. Pediatric burn patients who were admitted to our tertiary pediatric burn center during the pandemic (March 10 to September 30, 2020) and the pre-pandemic periods (March 10 to September 30, 2019) were included in our study. The patients were divided into two groups: the pandemic period and the pre-pandemic period. The groups were compared in terms of age, gender, city of origin, means of transport to the hospital, total burn surface area (TBSA), burn etiology, duration of hospitalization, intubation status, and mortality from their hospital medical records.

Cases that were admitted to our emergency department by their own parents and referred to our clinic with the 112 ambulance service for burns were evaluated. First, the burn areas of the patients were evaluated and dressed the wounds with protective equipment (Figure 1). Patients with indications for hospitalization were hospitalized to isolated single rooms in the burn intensive care unit. A symptom questionnaire was administered, and sampling for the COVID-19 polymerase chain reaction (PCR) test was performed on each patient admitted to the pediatric burn intensive care unit. The subsequent dressing and surgical procedures of the patients were performed in the operating room located in the burn center.

\section{Statistical Analysis}

Statistical analysis was done by using IBM SPSS 24.0 for Windows. Descriptive statistics (frequency, standard

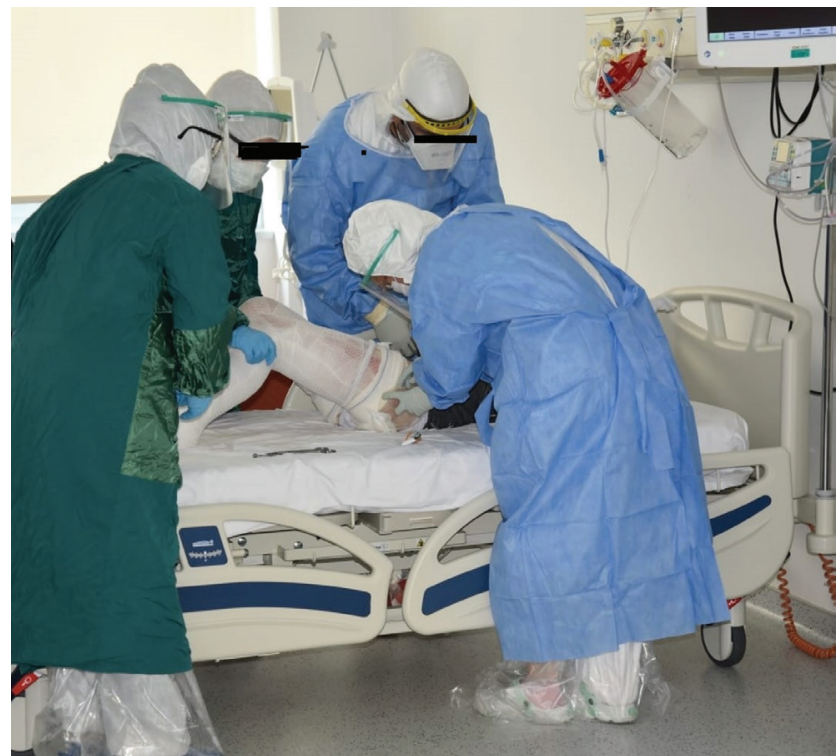

Figure 1. Wound dressing of a burn patient with protective equipments. It is published with the consent of the patient's parents.

deviation, and average) were used in the evaluation of data. Kolmogorov-Smirnov and Shapiro-Wilk tests were done for determining the normal distribution. Age, TBSA, and hospitalization day distributions were not normal and non-parametric tests were done (Mann-Whitney $U$ test) for comparing the groups. Pearson's chi-square test was done to determining the statistical significance of the differences between the averages of the groups in nominal values. The results were evaluated by a $95 \%$ confidence interval and $p<0.05$ significance level.

\section{Results}

In this study, 224 burned children who were hospitalized and treated in our pediatric burn unit were categorized into two groups: the pandemic period group (who were under curfew due to the COVID-19) and the pre-pandemic period group. In the pandemic period group, 414 children with burns were admitted to the pediatric burn unit, and 126 (30.4\%) children were hospitalized; however, in the pre-pandemic period group, 728 children with burns were admitted to the pediatric burn unit, and 98 (13.4\%) were hospitalized $(p<0.01)$. During the pandemic period, the COVID-19 PCR tests of two patients, one of them a 17-yearold girl and the other a 3-year-old male, were positive. The COVID-19 PCR results of other patients hospitalized in our center were found to be negative. The demographic data of the patients in the groups were detailed in Table 1.

When the patients were evaluated in terms of gender, the number of men was higher in both groups. The median age was $2.25 /(0.50-18)$ years in the pandemic period group, it was $2.50(0.3-16)$ years in the pre-pandemic 
period group ( $p>0.05)$. The ratio of children aged 1-5 years was higher in both groups (Table 2).

The patients were also evaluated according to the city which they came from (Table 3). While the number of patients coming from Ankara was higher in the pandemic period group, the number of patients referred from the other cities was higher in the pre-pandemic period, and there was a statistically significant difference $(p=0.04)$.

Patients were evaluated according to transportation to the hospital (Table 4). Although transport with 112 emergency ambulances services was more common in both groups, the rate of transport by private vehicle in the pandemic period group was statistically higher than prepandemic group $(p=0.005)$.

\begin{tabular}{|c|c|c|c|}
\hline & $\begin{array}{l}\text { Pre-pandemic } \\
\text { group } \\
\text { (March } \\
\text { 10-September } \\
30,2019 \text { ) }\end{array}$ & $\begin{array}{l}\text { Pandemic } \\
\text { group } \\
\text { (March } \\
\text { 10-September } \\
30,2020 \text { ) }\end{array}$ & p \\
\hline $\begin{array}{l}\text { Number of admitted } \\
\text { patients }\end{array}$ & 728 & 414 & 0.001 * \\
\hline $\begin{array}{l}\text { Number of hospitalized } \\
\text { patients }\end{array}$ & 98 & 126 & 0.001 * \\
\hline Gender (male/female) & $61 / 37$ & $81 / 45$ & $0.75^{\star}$ \\
\hline Age (median/range) & $\begin{array}{l}2.50(0.3-16) \\
\text { years }\end{array}$ & $\begin{array}{l}2.25 /(0.50-18) \\
\text { years }\end{array}$ & $0.53^{* *}$ \\
\hline TBSA (median/range) & $12.00(1-75)$ & $8.00(1-70)$ & 0.03 ** \\
\hline $\begin{array}{l}\text { Duration of } \\
\text { hospitalization } \\
\text { (median/range) }\end{array}$ & $\begin{array}{l}11.00(1-83) \\
\text { days }\end{array}$ & $\begin{array}{l}7.00(1-75) \\
\text { days }\end{array}$ & $0.03^{* *}$ \\
\hline $\begin{array}{l}\text { Number of intubated } \\
\text { patients }\end{array}$ & $17(17.34 \%)$ & $7(5.55 \%)$ & $0.005^{*}$ \\
\hline Mortality (\%) & $5(5.10 \%)$ & $4(3.1 \%)$ & $0.45^{\star}$ \\
\hline \multicolumn{4}{|c|}{$\begin{array}{l}{ }^{*}=\text { Pearson's chi-square test, }{ }^{* *}=\text { Mann-Whitney U test, TBSA: Total burn surface } \\
\text { area }\end{array}$} \\
\hline
\end{tabular}

\section{Table 2. Distribution of patients by age range}

\begin{tabular}{|c|c|c|c|c|c|}
\hline & $0-1$ years & $\begin{array}{l}1.1-5 \\
\text { years }\end{array}$ & $>5$ years & Total & p \\
\hline $\begin{array}{l}\text { Pre-pandemic } \\
\text { group }\end{array}$ & $23(23.5 \%)$ & $\begin{array}{l}51 \\
(52.0 \%) \\
\end{array}$ & $\begin{array}{l}24 \\
(24.5 \%) \\
\end{array}$ & 98 & \multirow{3}{*}{$0.56^{*}$} \\
\hline $\begin{array}{l}\text { Pandemic } \\
\text { group }\end{array}$ & $27(21.4 \%)$ & $\begin{array}{l}60 \\
(47.6 \%)\end{array}$ & $\begin{array}{l}39 \\
(31.0 \%)\end{array}$ & 126 & \\
\hline Total & 50 & 111 & 63 & 224 & \\
\hline
\end{tabular}

Table 3. Distribution of patients according to the city of origin

\begin{tabular}{|l|l|l|l|l|}
\hline Group & Ankara & Other cities & Total & p \\
\hline Pre-pandemic & $44(44.9 \%)$ & $54(55.1 \%)$ & 98 & \multirow{2}{*}{.04 $^{\star}$} \\
\hline Pandemic & $74(58.7 \%)$ & $52(41.3 \%)$ & 126 & \\
\cline { 1 - 4 }
\end{tabular}

$*=$ Pearson's chi-square test. In the pandemic group, the number of patients from Ankara is statistically higher than the pre-pandemic group
The median TBSA was statistically higher in the prepandemic group (12\%) than in the pandemic group (8\%; $p=0.03$ ). Scald burns were the most common cause of burns in both groups. The distribution of the groups according to burn etiology was detailed in Table 5. There was no statistically significant difference between the groups in terms of burn etiology ( $p>0.05)$. The median duration of hospitalization was statistically higher in the pre-pandemic group (11.0 days) than in the pandemic group ( 7.0 days) ( $p=0.03)$.

Intubated patient and mortality rates of groups were given in Table 1. The intubated patient rate in the pandemic group (17.34\%) was statistically higher than the pre-pandemic group $(p=0.005)$. The mortality rate was $3.1 \%$ in the pandemic group and $5.1 \%$ in the prepandemic group ( $p>0.05)$.

\begin{tabular}{|c|c|c|c|c|}
\hline Group & $\begin{array}{l}112 \text { emergency } \\
\text { ambulance }\end{array}$ & $\begin{array}{l}\text { Private } \\
\text { vehicle }\end{array}$ & Total & $p$ \\
\hline Pre-pandemic & 75 (76.5\%) & $23(23.5 \%)$ & 98 & \multirow{2}{*}{$0.005^{\star}$} \\
\hline Pandemic & 74 (58.7\%) & $52(41.3 \%)$ & 126 & \\
\hline
\end{tabular}

\begin{tabular}{|l|l|l|l|}
\hline \multicolumn{4}{|l|}{ Table 5. Distribution of patients according to burn etiology } \\
\hline & $\begin{array}{l}\text { Pre-pandemic } \\
\text { group } \\
\text { (March } \\
\text { 10-September 30, } \\
\text { 2019) }\end{array}$ & $\begin{array}{l}\text { Pandemic group } \\
\text { (March } \\
\text { 10-September 30, } \\
\text { 2020) }\end{array}$ & $\mathbf{p}^{*}$ \\
\hline Scald burns & $69(70.3 \%)$ & $93(73.7 \%)$ & 0.32 \\
\hline Contact burns & $3(3 \%)$ & $1(0.7 \%)$ & 0.20 \\
\hline Flame burns & $13(13.2 \%)$ & $23(18.2 \%)$ & 0.46 \\
\hline $\begin{array}{l}\text { Flame-inhalation } \\
\text { burns }\end{array}$ & $2(2 \%)$ & $1(0.7 \%)$ & 0.42 \\
\hline Electric burns & $11(11.2 \%)$ & $7(5.5 \%)$ & 0.12 \\
\hline Chemical burns & $1(1 \%)$ & $1(0.7 \%)$ & 0.85 \\
\hline Total & 98 & 126 & \\
\hline *= Pearson's chi-square test & & \\
\hline
\end{tabular}

\section{Discussion}

The COVID-19 pandemic has altered the professional and personal lives of many individuals, especially health professionals. In our country, the first COVID-19 case was detected on March 10, 2020. On March 16, 2020, curfew restrictions were applied for children, and the schools were closed. During the pandemic, children mostly spent time at home with their families. As a result, with such changes in daily life, hospital admission patterns were affected. 
A burn is a type of trauma that requires emergency intervention. Burn clinics have developed strategies for the COVID-19 pandemic in the treatment of patients with severe burns in general operating rooms and patients with stable, small, and uncomplicated burns as outpatients (5). It was reported that all burn patients who admitted to the hospital were screened for COVID-19 (5). During this period, we adopted the approaches shown in the literature for all burned patients who were admitted to our burn care center. Specifically, we took samples for COVID-19 testing from every admitted patient who was hospitalized at our burn center.

It was thought that in the lockdown period, family members would be at home so that children would have less risk of burning and would be more protected by family members. A variety of factors, including loss of social connections and family support, stress of working from home, and a lack of structured child care environments with reduced supervision of children, could cause severe burn injuries in children (6). There are many articles in the literature showing how pediatric burn centers have been affected during the COVID-19 pandemic. Studies from the UK and Morocco reported a 50\% reduction in the number of patients in the period March-June 2020 compared to the same period of the previous year (7). In contrast, in Turkey and the United States, there was a significant increase in the number of pediatric hospitalizations due to burns during the COVID-19 pandemic $(6,8)$. In a Brazilian study, it was shown that there was no difference in hospitalizations due to burns (9). In our study, it was observed that the number of patients who admitted to our center decreased at a statistically significant rate in the pandemic period compared to the pre-pandemic period $(p<0.01)$, but the number of patients who were hospitalized and followed up increased statistically $(p<0.01)$. In the pandemic period, the rate of patients referred from other cities was lower than in the pre-pandemic period $(p=0.04)$. We think that the decrease in admission to our burn center in the pandemic period is due to the parents' not admit the children with mild burns to our center with fear of COVID-19 transmission. However, various factors, such as burn depth, burn percentage, circular extremity burn, socioeconomic reasons, and serious and infected burns that parents think they couldn't treat at home, may have played a role in the increase in the hospitalization rate.

In this study, we determined that the median of TBSA, the duration of the hospitalization of the patients, and the intubated patient ratio in the pandemic group were statistically lower than in the pre-pandemic group. In the pandemic group, although most of the patients were operated on, the duration of hospitalization was shorter, and early discharges were approved. In a similar study conducted in North Israel by Kruchevsky et al. (10) it was observed that TBSA and hospitalization rates did not increase. Reasonable scientific evidences for the increase in the number of burn deaths during the pandemic period were not found in the literature (9). Also, in our study, there was no statistically significant difference in the mortality rate between groups $(p=0.45)$. So that, we should state that the COVID-19 pandemic does not affect the mortality of child burns.

It is known that boys are more exposed to burn trauma (11). In our study, we found that boys were more than girls in both groups, in accordance with the literature. In terms of gender, there was no statistically significant difference between the groups $(p=0.75)$. Many studies have shown that the most common burns in children are between the ages of 1 and 5 (12-14). In accordance with the literature, in our study, it was observed that the patients' age were mostly between the ages of 1 and 5 in both groups. There was no statistically significant difference between the groups in terms of age $(p=0.53)$ and age distributions $(p=0.56)$.

Studies have shown that the majority of childhood burns are caused by accidents in the home environment $(15,16)$. The most common place for burn injuries is the kitchen $(15,16)$. Burns may occur in children mostly due to hot liquids (mostly hot tea in our country), including hot oil on the kitchen counters or hot tap water in the bathroom. Potential reasons for burn in children include reduction and loss of social relationships and family support, the stress of working from home, and lack of suitable childcare environments (6). When patients were evaluated in terms of burn etiology, we determined that scalds were the most common cause of burns in the two groups in this study. In the pre-pandemic group, we found that contact, and electrical burns were more common than they were in the pandemic group, however flame burns ratios were more common in the pandemic group. However, there was no statistically significant difference betwwen thee groups in terms of burn etiology ( $p>0.05)$. We can attribute the increase in flame burns in the pandemic period to the fact that children were spending more time at home due to the curfew.

In the study, we observed that the number of patients referred from other cities decreased, and the patients coming from Ankara for hospitalization mostly with their own vehicles in the pandemic period.

\section{Study Limitations}

Our study clearly has some limitations. It was retrospective and conducted in a single-center. Furthermore, the study period was limited to six months. However, despite these limitations, the study will contribute to the literature with aspects such as showing how pediatric 
burns are affected by the COVID-19 pandemic and hence we are a pediatric burn reference center in our region, the variety and number of patients is high.

\section{Conclusion}

Compared to the pre-pandemic period, it was observed that the rate of hospitalization to our burn center increased in the pandemic period. However, it was determined that burned patients in the pandemic period were mild cases compared to the pre-pandemic period. The first reason for this increase is that burned patients who needed hospitalization were referred from other hospitals and pediatric burn units to our clinic, because they did not admit in the pandemic period. The second reason was that patients who were not hospitalized before but were followed up as outpatient, were hospitalized and isolated due to the risk of transmitted the COVID-19 infection in the control examination. In order to prevent this accumulation in future pandemic periods, treatment of burn patients should be provided in primary and secondary health care centers.

\section{Authorship Contributions}

Concept: H.C.O., S.K.Y., Design: M.N.A., E.S., Data Collection or Processing: M.E.O., T.J., G.K., Analysis or Interpretation: S.D., A.E., D.G., Literature Search: C.I.O., S.A.B., E.E.E., Writing: C.I.O., S.A.B., E.S.

Conflict of Interest: No conflict of interest was declared by the authors.

Financial Disclosure: The authors declared that this study received no financial support.

\section{References}

1. Al-Benna S, Gohritz A. Availability Of COVID-19 Information From National And International Burn Society Websites. Ann Burns Fire Disasters 2020;33:177-81.

2. Senaylı A, Köremezli H, Keskin G, Demir S, Azılı MN, Senel E. Various Types of Enteral Feeding for Burned Pediatric Patients and Their Clinical Consequences with Anaesthesia. Turkish Journal of Pediatric Disease 2016;10:241-3.

3. Ryder C, Mackean T, Hunter K, Rogers K, Holland AJA, Ivers R. Burn Injuries in Hospitalized Australian Children-An Epidemiological Profile. J Burn Care Res 2021;42:381-9.
4. Wilder-Smith A, Freedman DO. Isolation, quarantine, social distancing and community containment: pivotal role for oldstyle public health measures in the novel coronavirus (2019nCoV) outbreak. J Travel Med 2020;27:taaa020.

5. Ilenghoven D, Hisham A, Ibrahim S, Mohd Yussof SJ. Restructuring burns management during the COVID-19 pandemic: A Malaysian experience. Burns 2020;46:1236-9.

6. Sethuraman $U$, Stankovic $C$, Singer $A$, et al. Burn visits to a pediatric burn center during the COVID-19 pandemic and 'Stay at home' period. Burns 2021;47:491-2.

7. Farroha A. Effects of COVID-19 pandemic on burns epidemiology. Burns 2020;46:1466.

8. Demircan M. Increased admissions and hospitalizations to pediatric burn center during COVID 19 pandemic. Burns 2021;47:487-8.

9. Valente TM, Ferreira LPS, Silva RAD, Leite JMRS, Tiraboschi FA, Barboza MCC. Brazil Covid-19: Change of hospitalizations and deaths due to burn injury? Burns 2021;47:499-501.

10. Kruchevsky D, Arraf M, Levanon S, Capucha T, Ramon $Y$, Ullmann Y. Trends in Burn Injuries in Northern Israel During the COVID-19 Lockdown. J Burn Care Res 2021;42:135-40.

11. Senel E, Polat AD, Yastı AC, Karacan CD. Çocuk Yanıklarında Mortaliteyi Etkileyen Temel Parametreler Ve Alınabilecek Önlemler. Türkiye Çocuk Hast Derg 2007;1:18-25.

12. Keshavarz M, Javanmardi F, Mohammdi AA. A Decade Epidemiological Study of Pediatric Burns in South West of Iran. World J Plast Surg 2020;9:67-72.

13. Armstrong $M$, Wheeler KK, Shi J, et al. Epidemiology and trend of US pediatric burn hospitalizations, 2003-2016. Burns 2021;47:551-9.

14. Ozkan Z, Alatas ET. Surgical management of burns and our clinical experiences. J Clin Exp Invest 2014;5:76-79.

15. Riedlinger DI, Jennings PA, Edgar DW, et al. Scald burns in children aged 14 and younger in Australia and New Zealandan analysis based on the Burn Registry of Australia and New Zealand (BRANZ). Burns 2015;41:462-8.

16. Drago DA. Kitchen scalds and thermal burns in children five years and younger. Pediatrics 2005;115:10-6. 